\title{
Effect of arthroplasty design on cervical spine kinematics: analysis of the Bryan Disc, ProDisc-C, and Synergy Disc
}

\author{
Bruno C. R. Lazaro, M.D., ${ }^{1}$ Kemal Yucesoy, M.D., ${ }^{2}$ Kasim Z. Yuksel, M.D., ${ }^{3}$ \\ Izabela KowalczyK, B.H.Sc. ${ }^{4}$ Doron Rabin, M.D., F.R.C.S.C., ${ }^{1}$ Marie Fink, B.Sc., ${ }^{1}$ \\ AND NeIL Duggal, M.D., F.R.C.S.C. 1 \\ ${ }^{1}$ Department of Clinical Neurological Sciences, Division of Neurosurgery; ${ }^{4}$ Department of Medical \\ Biophysics, The University of Western Ontario, London, Ontario, Canada; ${ }^{2}$ Department of Neurosurgery, \\ Faculty of Medicine, Dokuz Eylul University, Izmir; and ${ }^{3}$ Department of Neurosurgery, Faculty of Medicine, \\ Kahramanmaras Sutcu Imam University, Kahramanmaras, Turkey
}

\begin{abstract}
Object. Cervical total disc replacement has emerged as a surgical option to preserve motion and potentially avoid adjacent-segment disease after anterior cervical discectomy and fusion. Recently, much attention has been directed at the ability of a given device to maintain and/or restore normal segmental alignment. Nonphysiological disc and segmental angulation could result in increased stresses transmitted to the facet joints and posterior elements, conflicting with the essence of arthroplasty and potentially leading to adjacent-segment disease. The goal of this study was to contrast device alignment and segmental kinematics provided by 3 different cervical disc prostheses.

Methods. Sixty patients were retrospectively analyzed and divided into 3 groups receiving the Bryan, ProDisc$\mathrm{C}$, or Synergy disc. Only single-level arthroplasty cases were included in the study. Lateral dynamic radiographs of the cervical spine were analyzed using quantitative motion analysis software (Medical Metrics, Inc.) to analyze the kinematics at the index level both preoperatively and postoperatively. Several parameters were noted, including range of motion, disc angles, shell angles, anterior and posterior disc heights, translation, and center of rotation. Preoperative and postoperative data were compared using the Student t-test with a significance level of $\mathrm{p}<0.05$.

Results. Postoperatively, all 3 disc groups maintained adequate range of motion at the implanted level. With respect to the shell angles, the Synergy disc demonstrated the least variability, maintaining $6^{\circ}$ lordotic configuration between the device endplates. In the Bryan disc group, significant shell kyphosis developed postoperatively $(\mathrm{p}<$ $0.0001)$. Both ProDisc-C and Synergy discs significantly increased anterior and posterior disc heights $(\mathrm{p}<0.0001)$. The Bryan and Synergy discs maintained the natural center of rotation, whereas significant anterior shift occurred with ProDisc-C.

Conclusions. The goal for motion preservation at the implanted level was achieved using all 3 devices. The Synergy disc was unique in its ability to alter device angulation by $6^{\circ}$. The Bryan disc demonstrated device endplate kyphosis. Both the Synergy disc and ProDisc-C increased disc space height. (DOI: 10.3171/2010.3.FOCUS1058)
\end{abstract}

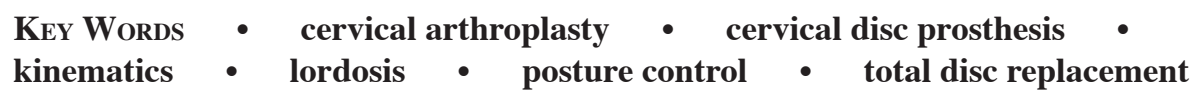

A NTERIOR cervical discectomy and fusion is considered the standard of care for treating radiculopathy and/or myelopathy due to DDD. The goals of this combined procedure are to decompress the neural structures, provide segmental stabilization, and restore or maintain lordotic alignment to optimize the chance of neurological recovery. ${ }^{15,23,31,46}$ Cervical TDR has emerged as an option to preserve motion and avoid potential adjacent-segment disease. ${ }^{4,8,11,13,18,21,28,48}$ To restore physiological biomechanics and reduce adjacent level forces, the goals of cervical arthroplasty must adhere to the same

\footnotetext{
Abbreviations used in this paper: $\mathrm{ACD}=$ anterior cervical discectomy; $\mathrm{ADH}=$ anterior disc height $\mathrm{COR}=$ center of rotation; $\mathrm{DA}=$ disc angle; $\mathrm{DDD}=$ degenerative disc disease; $\mathrm{PDH}=$ posterior disc height; $\mathrm{ROM}=$ range of motion; $\mathrm{SA}=$ shell angle; TDR = total disc replacement.
}

surgical principles, with the exception of motion preservation - that is, decompress neural structures, maintain intervertebral motion, and restore or maintain segmental lordosis. Although a number of currently available cervical TDRs provide evidence of in vivo ROMs, only isolated devices have specifically incorporated lordosis correction into the device design specifications..$^{29,31,32,35,36,41}$

Cervical arthroplasty devices come in a variety of designs that provide different kinematic properties once implanted. ${ }^{31}$ The ProDisc-C disc (Synthes Spine, Inc.) is a cobalt-chrome on polyethylene ball-in-socket single-articulating device that maintains a fixed COR. ${ }^{12}$ With such devices, posterior placement is essential, whereas devices that allow a mobile COR have the theoretical advantage of providing normal kinematics over a range of device positions. In contrast, the Bryan disc (Medtronic Sofamor Danek) consists of a low-friction polyurethane core 


\section{B. C. R. Lazaro et al.}

situated between 2 titanium alloy shells and surrounded by a polyurethane sheath. It has double articulation surfaces and independent translation, allowing a mobile instantaneous axis of rotation. Pickett et al. ${ }^{33}$ first demonstrated a mobile COR in an in vivo kinematic analysis of radiographs obtained in patients undergoing cervical TDR with the Bryan disc. The Synergy cervical disc (Synergy Disc Replacement, Inc.) incorporates a novel geometry allowing controlled deformity correction in the sagittal and coronal planes while restoring physiological biomechanics and ROM (Fig. 1). The Synergy disc has a titanium-on-polyethylene articulation with a mobile COR and varying degrees of lordotic correction incorporated into the polyethylene core to provide reliable, predictable correction of cervical alignment.

Despite initial positive clinical results, several reports have documented the occurrence of Bryan disc endplates kyphosis. ${ }^{22,32,34,42,43}$ Several studies have demonstrated a correlation between cervical kyphosis, axial neck pain, new-onset neurological symptoms, segmental instability, and poor functional outcome. . $^{1,23,25,32}$ Although authors of recent analyses have reported increased lordosis at the site implanted with the ProDisc-C, ${ }^{2,3}$ Rabin et al..$^{35}$ showed that a lordotic configuration of ProDisc-C endplates was associated with a restricted segmental ROM and translation from neutral to extension. Given that segmental angulation can be influenced by a variety of technical factorsincluding the amount of endplate drilling, removal of the anterior lip of the superior vertebral body, intraoperative positioning, device angle insertion, and anterior-posterior depth of implantation ${ }^{49}$ - the next generation of cervical TDR designs must incorporate strategies to provide reliable, predictable correction of cervical alignment along with the restoration of physiological biomechanics..$^{3,19,49}$

In this in vivo retrospective study we analyzed device alignment and segmental kinematics to compare the quality of motion and device angulation provided by 3 differing cervical disc prostheses. A better understanding of the different device designs will ultimately lead to refined indications and device selection with a focus on improving the quality of motion.

\section{Methods}

The Health Sciences Research Ethics Board at the University of Western Ontario approved this study.

\section{Patient Population}

Prospective upright (standing) lateral flexion and extension cervical radiographs were obtained in consecutive patients undergoing a single-level ACD followed by cervical TDR. Patients with symptomatic cervical spondylosis demonstrating evidence of retained motion at the affected level on preoperative radiographs were offered cervical arthroplasty as an alternative to arthrodesis. Those with axial neck pain as the predominant or solitary symptom were not offered surgery.

Patients were selected for inclusion in this study based on the following criteria: 1) objective clinical evidence of single-level cervical disc disease causing cervical radiculopathy and/or myelopathy, 2) radiographic
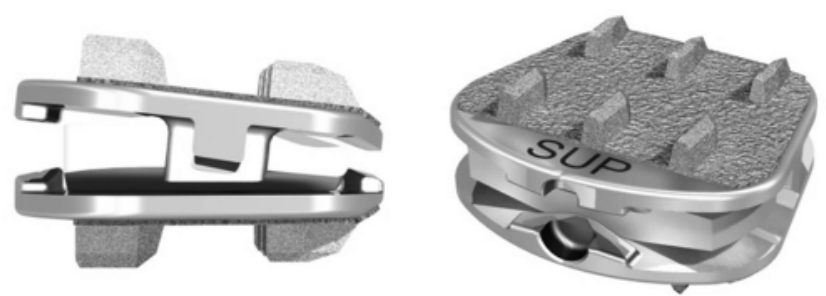

Fig. 1. Illustration of the Synergy disc showing its unique design, which allows the device endplates to maintain a $6^{\circ}$ lordotic configuration in the neutral position.

evidence of single-level cervical DDD, 3) no response to nonsurgical management for $>12$ weeks, 4) a minimum of 6 months of postoperative radiographic followup, and 5) a preoperative ROM at the target level $>2^{\circ}$. Patients with traumatic or infectious pathology, clinically or radiographically demonstrated multilevel disc disease, radiographically demonstrated instability, severe facet disease, previous cervical spine surgery, and incomplete data at the last follow-up were excluded. To prevent postoperative pain from impacting the effort of postoperative dynamic cervical radiographs, a minimum of 6 months of follow-up was 1 of the criteria used for patient inclusion in the study. During the period of consecutive patient recruitment, no patient dropped out of treatment and no revision surgery was performed. No patient with a poor clinical outcome or poor disc placement was excluded from the study.

Images from the first 60 consecutive patients undergoing single-level cervical arthroplasty using the ProDisc-C, Bryan, or Synergy discs were selected and retrospectively analyzed in this study; each disc type had been inserted in 20 patients. Standard presurgical assessments included clinical history, neurological examination, and MR imaging. Static and dynamic upright (standing) neutral and flexion and extension cervical radiographs were obtained preoperatively and at 6-12 months postoperatively to assess device kinematics and alignment. Our radiographic technique has been described elsewhere. ${ }^{32}$

\section{Surgical Procedure}

A standard right-sided cervical approach for ACD was performed in all patients. Selection of the arthroplasty device was dependent on availability. All devices were implanted as suggested in the product monographs.

\section{Radiographic Analysis}

Preoperative and the latest postoperative flexion and extension and neutral lateral cervical radiographs were analyzed for each of the disc groups. Independent quantitative motion analysis software (Medical Metrics, Inc.) was used to analyze the kinematics at the index levels. This validated radiographic software uses advanced pattern recognition algorithms to generate accurate measurements of ROM, DA, SA, ADH, PDH, sagittal plane translation, and COR. ${ }^{39,40}$ The SA was defined as the angle between the superior and inferior endplates of the cervical TDR. The COR was obtained for the index and 
TABLE 1: Summary of patient data

\begin{tabular}{lccc}
\hline \multicolumn{1}{c}{ Measure } & ProDisc-C & Bryan Disc & Synergy Disc \\
\hline $\begin{array}{l}\text { no. of patients } \\
\text { age (yrs) }\end{array}$ & 20 & 20 & 20 \\
$\quad$ mean & $46.5 \pm 8.4$ & $43 \pm 6.6$ & $45.8 \pm 9.0$ \\
range & $36-66$ & $32-56$ & $29-60$ \\
sex (\% of group) & & & \\
M & $6(30)$ & $12(60)$ & $9(45)$ \\
F & $14(70)$ & $8(40)$ & $11(55)$ \\
levels (\% of group) & & & \\
C3-4 & 0 & $1(5)$ & 0 \\
C4-5 & $1(5)$ & $1(5)$ & $2(10)$ \\
C5-6 & $11(55)$ & $9(45)$ & $14(70)$ \\
C6-7 & $8(40)$ & $9(45)$ & $4(20)$ \\
\hline
\end{tabular}

adjacent spinal levels and was reported as $\mathrm{X}$ and $\mathrm{Y}$ offset from the midline of the superior endplate of the caudal vertebral body. ${ }^{32,33}$

\section{Statistical Analysis}

The means \pm SD were determined for ROM, DA, $\mathrm{SA}, \mathrm{ADH}, \mathrm{PDH}$, translation, COR $\mathrm{X}$, and COR Y. The ANOVA was used to compare results between the 3 disc groups. Further analysis was completed using the Student t-test. A p value $<0.05$ was considered significant.

\section{Results}

\section{Patient Population}

All selected patients met the inclusion criteria. Sixty patients (27 men and 33 women) with a mean age of 45.1 years (range 29-66 years) were included in the study (Ta- ble 1). The mean follow-up was 12 months (range 6-24 months). No patients or data were lost at the follow-up. Each patient underwent a single-level disc arthroplasty, receiving 1 of the following disc types: ProDisc-C, Bryan, or Synergy disc. Cervical TDRs were performed from C-3/C-4 to C-6/C-7. There was immediate relief of radiculopathy and/or myelopathy in all cases, with no operative or device-related complications. No delayed complications were observed. All imaging studies had been prospectively collected during the latest follow-up visit and were compared with preoperative radiographs.

\section{Range of Motion}

Preoperatively, the patients in the ProDisc-C group had the least ROM. Postoperatively, this group demonstrated a significant increase in the segmental ROM from extension to flexion (preoperative mean $8.0 \pm 4.0^{\circ}$ vs postoperative mean $10.7 \pm 5.5^{\circ}, \mathrm{p}=0.0003$ ). In cases in which hyperlordosis of the endplates was found in the neutral position, the component ROM demonstrated unequal ROM from neutral to flexion and neutral to extension (Fig. 2). Bryan disc insertion maintained segmental $\mathrm{ROM}$ (preoperative $9.5 \pm 4.9^{\circ}$ to postoperative $8.1 \pm 4.3^{\circ}$, $\mathrm{p}=0.23$ ). The Synergy group had the largest preoperative $\operatorname{ROM}\left(11.1 \pm 5.2^{\circ}\right)$. Following surgery, there was no change in the ROM from extension to flexion $\left(8.9 \pm 4.4^{\circ}\right.$, $\mathrm{p}=0.06$ ). There was no difference in ROM among the 3 devices.

\section{Disc Angle and SA}

The mean preoperative DA for the entire cohort of 60 patients was $2.9 \pm 4.3^{\circ}$. The DA represents the angle of the diseased disc space prior to surgery.

The ProDisc-C preoperative DA at the surgical level was almost parallel at $1.2 \pm 3.3^{\circ}$. Following surgery, the mean device SA was $1.1 \pm 3.6^{\circ}(\mathrm{p}=0.64)$. The postoperative SA was variable, with 3 patients $(15 \%)$ demonstrating a $>2^{\circ}$ worsening of kyphosis at the latest follow-up and 3 patients $(15 \%)$ exhibiting postoperative hyperlordosis (SA $>5^{\circ}$; Fig. 2).
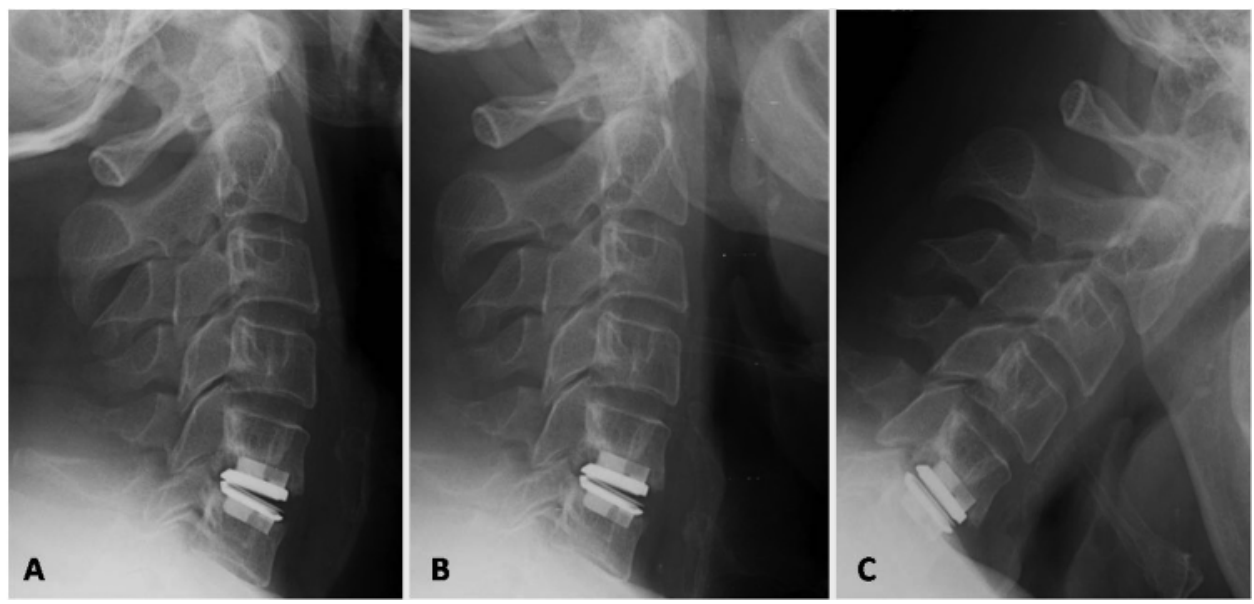

FiG. 2. Extension (A), neutral (B), and flexion (C) lateral radiographs demonstrating SA hyperlordosis in the neutral posture following ProDisc-C insertion. Placement of this disc results in unequal motion, with the neutral to flexion ROM of $8^{\circ}(\mathrm{B}-\mathrm{C})$ but a limited ROM from neutral to extension of $1.2^{\circ}(\mathbf{A}-\mathbf{B})$. 


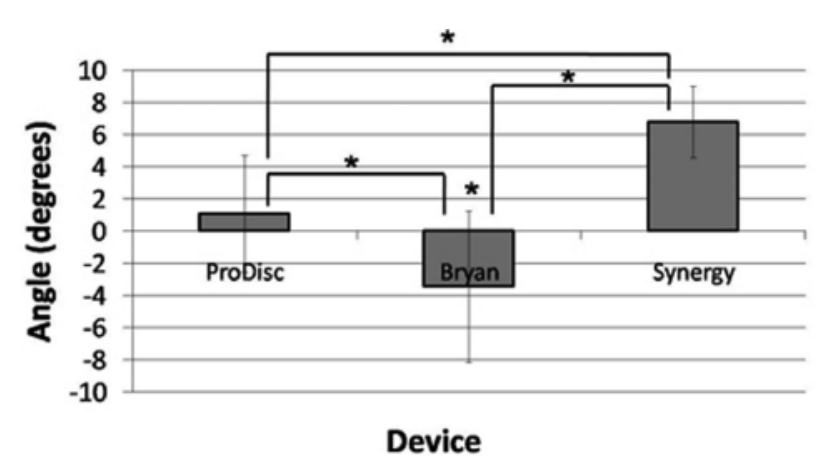

FIG. 3. Bar graph demonstrating the late follow-up SA following insertion of a cervical TDR. Bars represent SDs. Asterisk represents a significance level of $p<0.05$.

In the Bryan disc group, the preoperative lordotic DA was $3.0 \pm 3.1^{\circ}$. Following insertion of the Bryan disc, significant SA kyphosis was found at the late follow-up (-3.4 $\pm 4.7^{\circ}, \mathrm{p}<0.0001$; Fig. 3$)$. An increase in kyphosis $\left(>4^{\circ}\right)$ at the index level in the neutral position was found in $60 \%$ of patients (Fig. 4).

The Synergy disc demonstrated the least variability with respect to SA. The Synergy disc has a number of lordotic core offerings; the core used in this study had a $6^{\circ}$ configuration. The preoperative DA for the Synergy group was $4.6 \pm 5.9^{\circ}$. Following insertion of the $6^{\circ}$ Synergy disc, the SA maintained a mean of $6.8 \pm 2.2^{\circ}(p=0.08)$.

A comparison of the SA between the ProDisc-C and Synergy disc groups revealed a statistically significant increase in lordosis with the Synergy device $(\mathrm{p}<0.0001$; Fig. 3). Both the ProDisc-C and Synergy discs showed a lordotic SA configuration when compared with the Bryan $\operatorname{disc}(\mathrm{p}=0.002$ and $<0.0001$, respectively).

\section{Disc Height}

Preoperatively, for the entire cohort of 60 patients, the mean $\mathrm{ADH}$ was $4.0 \pm 1.1 \mathrm{~mm}$, whereas the mean
PDH was $3.1 \pm 0.9 \mathrm{~mm}$. At the surgical level the ADH increased by $80 \%(3.4 \pm 1.0 \mathrm{~mm}$ preoperatively vs $6.1 \pm$ $1.0 \mathrm{~mm}$ postoperatively, $\mathrm{p}<0.0001$ ) following insertion of the ProDisc-C, whereas the PDH increased by $52 \%$ $(3.1 \pm 0.9 \mathrm{~mm}$ preoperatively vs $4.7 \pm 0.7 \mathrm{~mm}$ postoperatively, $\mathrm{p}<0.0001)$. In contrast, following insertion of the Bryan disc, the ADH decreased by $32 \%(4.4 \pm 1.0$ $\mathrm{mm}$ preoperatively vs $3.0 \pm 1.1 \mathrm{~mm}$ postoperatively, $\mathrm{p}<$ $0.0001)$, whereas the PDH decreased by $14 \%(3.5 \pm 0.9$ $\mathrm{mm}$ preoperatively vs $3.0 \pm 1.0 \mathrm{~mm}$ postoperatively, $\mathrm{p}=$ $0.0005)$. With the Synergy disc there was a $48 \%$ increase in the $\mathrm{ADH}(4.0 \pm 1.0 \mathrm{~mm}$ preoperatively vs $6.0 \pm 1.3$ $\mathrm{mm}$ postoperatively, $\mathrm{p}<0.0001$ ) and a $32 \%$ increase in the PDH $(2.8 \pm 0.9 \mathrm{~mm}$ preoperatively vs $3.8 \pm 1.1 \mathrm{~mm}$ postoperatively, $\mathrm{p}=0.0003$ ).

In comparing the 3 devices, there was no significant difference in ADH between the ProDisc-C and Synergy disc. Both of these disc types presented a significant increase in the $\mathrm{ADH}$ and $\mathrm{PDH}$ when compared with the heights for the Bryan disc $(\mathrm{p}<0.0001)$. All 3 devices differed from each other with respect to the PDH $(\mathrm{p}<0.05$ for all).

\section{Sagittal Plane Translation}

The ProDisc-C disc demonstrated translation of 1.5 $\mathrm{mm}(0.7 \pm 0.5 \mathrm{~mm}$ preoperatively vs $1.5 \pm 0.6 \mathrm{~mm}$ postoperatively, $\mathrm{p}<0.0001)$. Changes in segmental translation induced by the Bryan disc were negligible $(\mathrm{p}=0.98)$. The Bryan disc had $1.0 \mathrm{~mm}$ of translation preoperatively and $1.0 \mathrm{~mm}$ postoperatively. The Synergy disc had the largest amount of preoperative translation at $1.4 \mathrm{~mm}$, almost double the preoperative translation seen in the ProDisc$\mathrm{C}$ patients preoperatively. After Synergy disc insertion, there was no significant change in translation at $1.2 \mathrm{~mm}$.

There was no difference in translation between the Synergy disc and the other 2 devices. Compared with the Bryan disc, there was increased translation in the ProDisc-C $(\mathrm{p}=0.03)$.
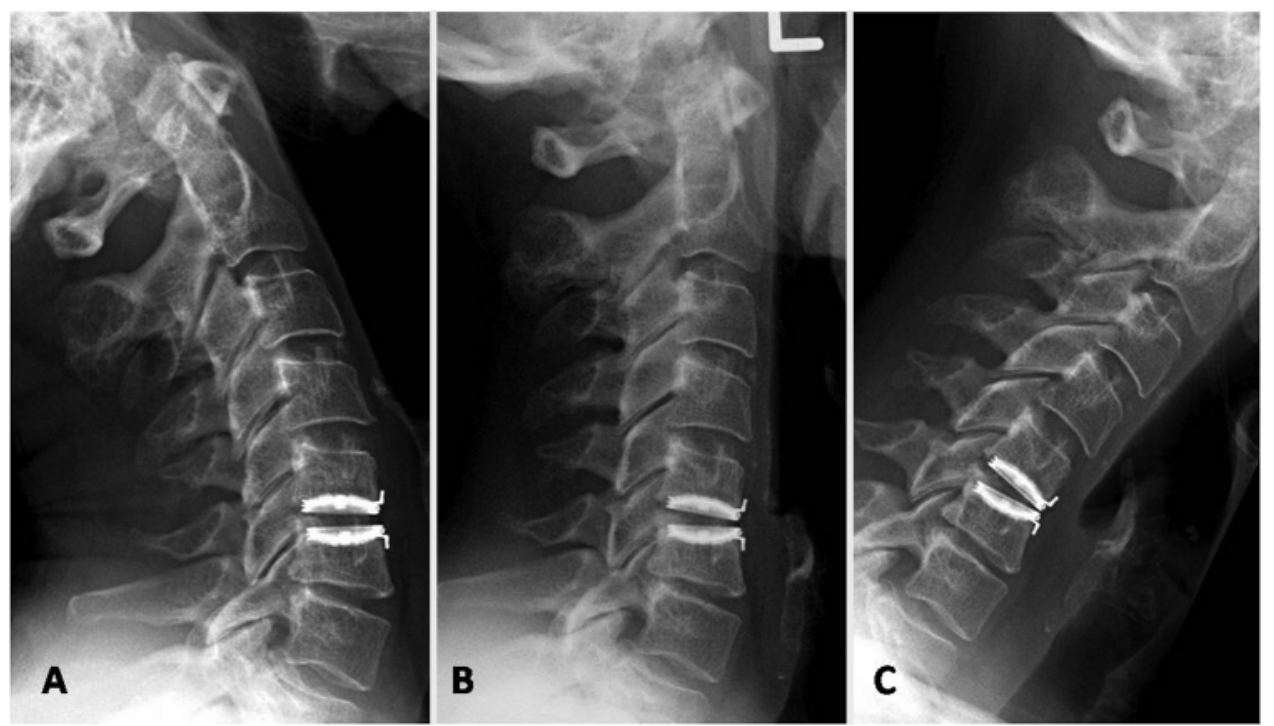

FıG. 4. Extension (A), neutral (B), and flexion (C) lateral radiographs demonstrating SA kyphosis in the neutral posture following Bryan disc insertion. 


\section{Analysis of Bryan, ProDisc-C, and Synergy discs}
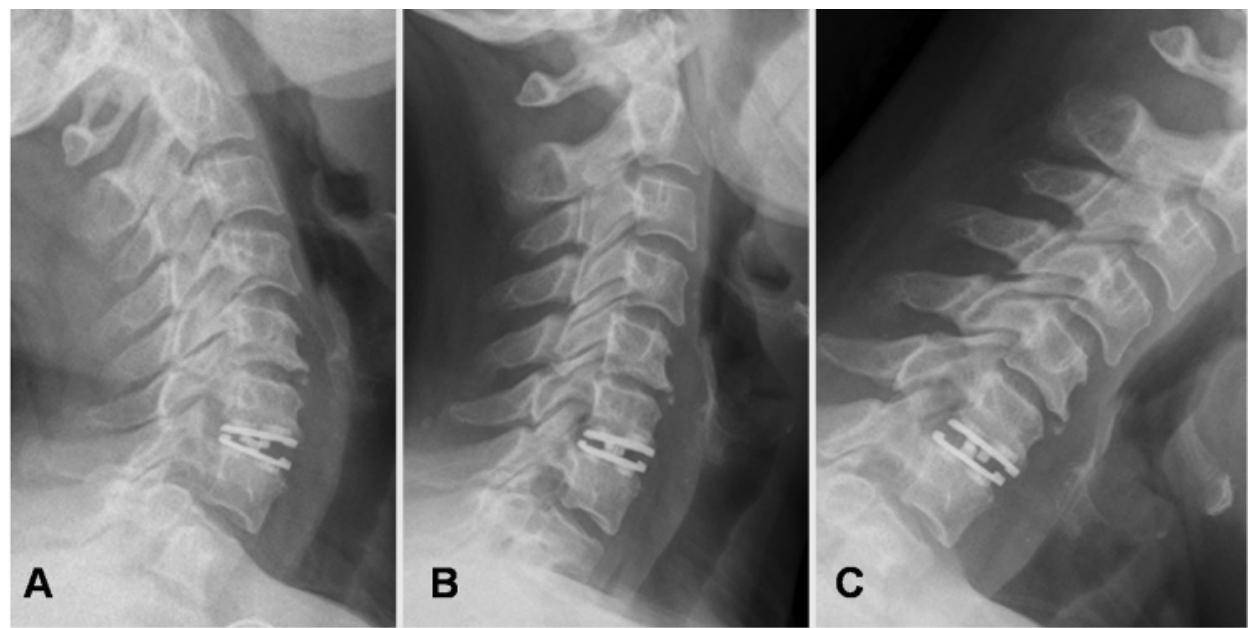

Fig. 5. Extension (A), neutral (B), and flexion (C) lateral radiographs obtained after Synergy disc insertion, demonstrating $14.2^{\circ} \mathrm{ROM}$ from extension to flexion (A-C). The SA in the upright (standing) neutral radiograph (B) demonstrates $6.2^{\circ}$ of lordosis.

\section{Center of Rotation}

At the surgical level, the COR X underwent a statistically significant anterior shift of $0.9 \mathrm{~mm}$ after the introduction of the ProDisc-C disc $(-0.8 \pm 1.2$ vs $0.2 \pm$ $0.8 \mathrm{~mm}, \mathrm{p}=0.002)$; there were no significant changes in the COR Y values $(p=0.99)$. The Bryan disc did not significantly change either the COR X or COR Y values ( $\mathrm{p}=0.16$ and 0.27 , respectively). Following insertion of the Synergy disc, the COR X underwent an anterior shift $(-0.9 \pm 0.9$ vs $-0.1 \pm 0.8 \mathrm{~mm}, \mathrm{p}=0.002)$. There were significant changes in the COR Y values $(3.9 \pm 2.2$ vs $2.7 \pm$ $2.5 \mathrm{~mm}, \mathrm{p}=0.006)$.

When comparing the 3 devices for the COR X and $\mathrm{Y}$, the only difference found was between the Bryan and Synergy disc for the COR X parameter $(\mathrm{p}=0.0006)$.

\section{Discussion}

Three cervical disc replacements with different concepts in design and biomechanics were retrospectively compared in this study. Range of motion, the fundamental parameter, was preserved at the implanted site in all devices. The greatest difference between the 3 devices was in the SA measurements. The ProDisc-C disc had a slightly lordotic SA of $1.1 \pm 3.6^{\circ}$, with $15 \%$ of patients demonstrating worsening kyphosis and $15 \%$ showing hyperlordosis (Fig. 2). In contrast, the Bryan disc demonstrated $-3.4 \pm 4.7^{\circ}$ of SA kyphosis, with $60 \%$ of patients exhibiting postoperative device endplate kyphosis (Fig. 4). According to the product monographs, to optimize ROM, both the ProDisc-C and the Bryan disc should be inserted into the disc space with the goal of keeping the device endplates in a parallel orientation. The Synergy disc has a unique design, allowing the device endplates to maintain a $6^{\circ}$ lordotic configuration in the neutral position while providing a full ROM (Fig. 5). The Synergy disc demonstrated the least variability in SA, with a mean of $6.8 \pm 2.2^{\circ}$.

The initial objective of cervical disc replacement was the maintenance of motion at the implanted level, therefore reducing the incidence of adjacent-level disease. Despite favorable short-term clinical results, insertion of the Bryan disc has prompted concerns regarding postop-

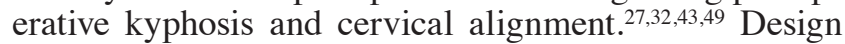
limitations and technical nuances can contribute to the poor results in segmental alignment found with the Bryan disc. ${ }^{42,43}$ Factors such as lordotic neck positioning, overdrilling and asymmetry of the vertebral endplates, angle of disc insertion, preexisting kyphosis, and the structural absence of lordosis in the device have been implicated in the development of postoperative kyphosis with the Bryan disc..$^{17,27,50}$ Studies involving long-term results in patients with cervical fusion have reported the new onset of axial symptoms and accelerated adjacent-segment disease related to focal and segmental kyphosis at the fused level. ${ }^{24,26}$ As stated by Kim et al., ${ }^{27}$ "the Bryan artificial disc prosthesis has a passive nature in its design, and is not designed to correct kyphosis; hence, one would expect that it would be unable to restore lordosis to [the] spine." In contrast, Rabin et al. ${ }^{35}$ showed that a lordotic configuration of ProDisc-C endplates at the surgical level was associated with restricted segmental ROM and translation from neutral to extension. Like the Bryan disc, the ProDisc-C was not designed to actively correct sagittal alignment. An emerging contraindication for cervical TDR is the presence of preoperative straightening or focal kyphosis at the index level. The Synergy disc is differentiated by its $6^{\circ}$ preferred lordotic orientation, designed specifically for its unique ability to correct preoperative deformity and/or maintain cervical lordosis (Fig. 6). Our results demonstrated that the Synergy disc maintained a $6.8^{\circ}$ lordotic SA alignment.

The preoperative DA for the entire patient cohort (60 patients) demonstrated a relative loss of lordosis due to the degenerative process $\left(2.9 \pm 4.3^{\circ}\right)$. Harrison et al..$^{20}$ studied 252 asymptomatic volunteers and found that the average lordosis between cervical vertebrae was between 6 and $7^{\circ}$. It is important to note that only healthy volunteers without clinical or radiographic signs of DDD were 

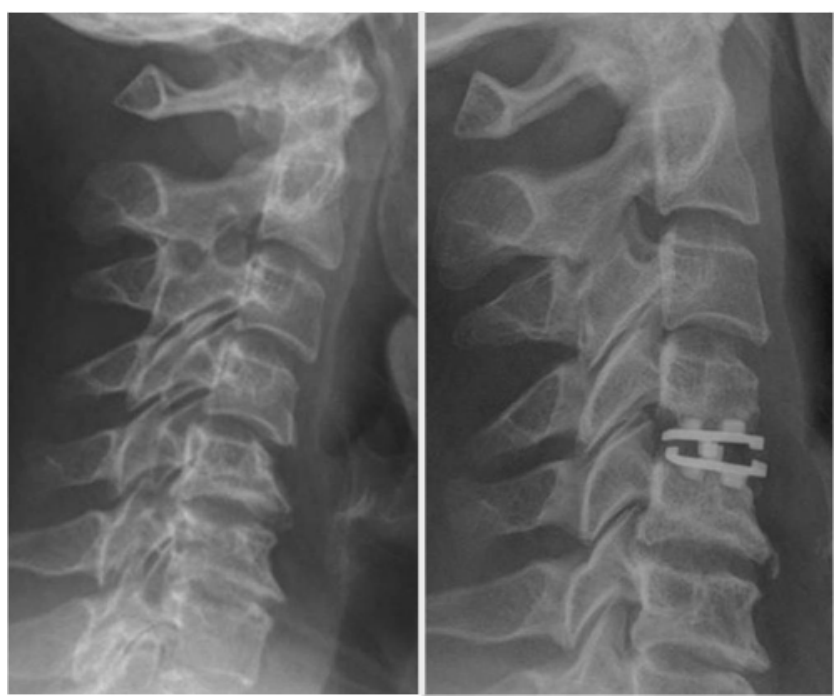

FIG. 6. Preoperative (left) and postoperative (right) lateral neutral radiographs demonstrating correction for preoperative focal kyphosis following insertion of the $6^{\circ}$ Synergy disc.

considered..$^{20}$ Degenerative disc disease is characterized by deterioration and collapse of the intervertebral disc $\mathrm{c}^{1,7,47}$ accompanied by alterations in the spinal curvature. ${ }^{14,30}$ Shim et al. ${ }^{44}$ reported a preoperative DA (at index level) of $-0.7^{\circ}$ (47 patients). Fong et al. ${ }^{17}$ studied 10 patients undergoing Bryan cervical disc arthroplasty and found that $40 \%$ had angles between 1 and $2^{\circ}$ lordosis and $30 \%$ were straight (parallel with $0^{\circ}$ ). Johnson et al..$^{22}$ studied 13 patients with a mean preoperative angle of $1^{\circ}$ and noted that the symptomatic segment was kyphotic because of a loss of ADH. Changes in disc height can contribute to the loss of the normal cervical lordosis seen in patients with DDD. 6,9,38 Traditional fusion strategies have incorporated techniques for the restoration of appropriate lordotic curvature..$^{24,37,45}$

Our results lend further evidence to previous studies whose data suggest that a loss of disc space height accompanies DDD. In the ProDisc-C group, the preoperative mean ADH and PDH were 3.4 and $3.1 \mathrm{~mm}$, respectively. For the Bryan and Synergy groups, larger differences were seen between the preoperative ADH and PDH values. Following arthroplasty, both the ProDisc-C and Synergy devices increased the ADH to approximately $6 \mathrm{~mm}$, whereas the Bryan disc decreased the ADH following surgery. Increasing the disc height is important in restoring adequate foraminal height and preventing recurrent nerve root compression. Overdistraction of the disc space, however, can be associated with "overstuffing" and may be associated with both diminished motion of the TDR and facet distraction causing neck pain. The Bryan disc ADH and $\mathrm{PDH}$ values were equal at $3.0 \mathrm{~mm}$. Despite the device size, the milling of the endplates required for device insertion may prevent the Bryan disc from restoring adequate disc height. Both the Synergy and ProDisc-C devices in this study had a device height of $5 \mathrm{~mm}$. By virtue of its design, the Synergy disc has unequal values for $\mathrm{ADH}$ and $\mathrm{PDH}$, as it has a configuration of a wedge with $6^{\circ}$ of lordosis designed into the polyethylene core (Fig. 1).
Range of motion, a fundamental kinematic parameter, was preserved at the index level for all discs: ProDisc-C $10.7 \pm 5.4^{\circ}$, Bryan $8.1 \pm 4.3^{\circ}$, and Synergy $8.9 \pm$ $4.4^{\circ}$. A comparison between the 3 devices demonstrated no significant difference in the ROM. The ProDisc-C added ROM to the preoperative level, increasing segmental motion by $34 \%$. However, the preoperative ROM for the ProDisc-C group was only $8.0 \pm 4.0^{\circ}$, whereas the preoperative ROM for the Bryan and Synergy groups was $>9.0^{\circ}$. Previous studies have already documented significant increases in in vivo and in vitro sagittal motion following insertion of the ProDisc-C. ${ }^{5,10,35}$ Bertagnoli et al. ${ }^{5}$ reported a significant in vivo increase in sagittal ROM $\left(4^{\circ}\right.$ preoperatively vs $12^{\circ}$ postoperatively) following insertion of the ProDisc-C. DiAngelo et al ${ }^{10}$ described in vitro biomechanical results in cadaveric cervical spines implanted with a single-level ProDisc-C and compared this strategy with single-level ACD and fusion. Following insertion of the ProDisc-C, the surgical level demonstrated a ROM of $13.1^{\circ} .{ }^{10}$ It is unclear whether there is any clinical benefit to increasing the ROM at the diseased level. In theory, increased ROM may place increased strain on facet joints and uncovertebral joints at the surgical level, potentially causing a negative effect on the index and adjacent-level facets and discs. Alternatively, increased ROM may reduce the potential for autofusion across the arthroplasty level. Longer follow-ups will be required to evaluate the impact of significantly increasing ROM at a functional spinal unit already diseased by the degenerative cascade.

In contrast to the ProDisc- $\mathrm{C}$, both the Bryan and Synergy discs did not change ROM at the index levels. This result may be related to device design with "constraints" incorporated into both devices. With the Bryan disc, a central post and outer membrane sheath limit both translation and ROM. With the Synergy disc, unique soft stops control and prevent excessive sagittal rotation, axial rotation, translation, and lateral bending. For example, in a patient who received a Synergy disc (Case 7; Fig. 6), the preoperative ROM was $19.3^{\circ}$. Following cervical TDR with Synergy, the ROM decreased to $10.6^{\circ}$. In addition to device design, the surgical technique can influence postoperative ROM for the device. Resection of the uncus and division of the posterior longitudinal ligament has been suggested to impact device ROM.

The ProDisc-C incorporates a ball-in-socket joint mechanism with a fixed axis of rotation. Hence, the quality of motion is strictly dependent on the anterior-posterior placement depth and alignment of the device endplates. The COR shifted anteriorly by $1.0 \mathrm{~mm}$ (COR X, p = 0.002). As expected, the Bryan disc preserved the physiological location of the COR. The Synergy disc also provided changes in the COR from the preoperative values. Caution must be applied while determining the importance of preserved CORs following cervical arthroplasty. The preoperative parameters observed in our studies cannot be taken as "normal" because all patients had symptomatic single-level disc disease. As such, the lack of significant change in biomechanical parameters in the Bryan disc between pre- and postoperative radiographs implies that the disc was able to maintain the existing preoperative biomechanical properties of the cervical spine. The 
prosthesis, being passive, adapted itself into the local biomechanical profile provided by adjacent vertebral bodies, ligaments, and facet joints. However, Synergy disc implantation resulted in increased disc height and a lordotic SA, changes that would impact COR coordinates when compared with preoperative values. These changes in the COR may represent further deviations from "normal" parameters or, alternatively, a closer approximation of the properties of a healthy native disc.

\section{Study Limitations}

Interpreting in vivo $\mathrm{x}$-ray-based kinematic analysis of spinal biomechanics should be approached with caution, especially in a small group of patients. Although kinematics software has demonstrated good reliability and accuracy, the analysis may be limited by patient factors. Out-of-plane motion, pain, and patient effort may introduce variability over sequential films. Patient body habits may obscure anatomical detail in the caudal cervical spine and contribute to error within all kinematic measures. ${ }^{33}$ This study addresses only flexion and extension ROM and does not characterize the biomechanical behavior of any of the devices in axial rotation or lateral bending. Analyzing patients after the first 6 months theoretically decreases the influence of postoperative pain and patient discomfort on overall sagittal motion, allowing the cervical prosthesis to settle and the muscles and facet joints to adapt. Also within the first 6 months postoperatively, device endplates are expected to incorporate with the vertebral endplates. Nonetheless, the short-term follow-up in this study, averaging only 12 months, does not address the durability of the devices nor the long-term quality of motion. Long-term evaluation of cervical arthroplasty will require merging of clinical, radiographic, and kinematic information to determine optimal device design.

\section{Conclusions}

While limited by a small sample size and a short postsurgical follow-up period, this in vivo study demonstrated that ProDisc-C, Bryan, and Synergy discs adequately maintain ROM at the implanted level. The greatest difference between the 3 devices was in the SA measurements; the Synergy disc provided a $6^{\circ}$ lordotic correction following insertion. In addition, there was an increase in the ADH and PDH after implantation of the ProDisc-C and Synergy discs. In contrast, the Bryan disc did not restore disc height and instead produced significant SA kyphosis at the implanted level. Preoperative COR values were fairly preserved among all devices. Longer follow-up is required to assess the durability of kinematic changes at the implanted levels following cervical TDR.

\section{Disclosure}

Dr. Duggal has received teaching honoraria/research support, consulting fees/shares, and fellowship/research support from Medtronic Sofamor Danek; Synergy Disc Replacement, Inc.; and Synthes Spine, Inc., respectively.

Author contributions to the study and manuscript preparation include the following. Conception and design: N Duggal, D Rabin. Acquisition of data: N Duggal, K Yucesoy, KZ Yuksel, I
Kowalczyk, D Rabin, M Fink. Analysis and interpretation of data: all authors. Drafting the article: N Duggal, BCR Lazaro, I Kowalczyk, D Rabin, M Fink. Critically revising the article: N Duggal, BCR Lazaro, I Kowalczyk. Reviewed final version of the manuscript and approved it for submission: N Duggal. Statistical analysis: K Yucesoy, KZ Yuksel, I Kowalczyk. Study supervision: N Duggal.

\section{References}

1. Adams MA, Roughley PJ: What is intervertebral disc degeneration, and what causes it? Spine 31:2151-2161, 2006

2. Ahn PG, Kim KN, Moon SW, Kim KS: Changes in cervical range of motion and sagittal alignment in early and late phases after total disc replacement: radiographic follow-up exceeding 2 years. Clinical article. J Neurosurg Spine 11:688-695, 2009

3. Anakwenze OA, Auerbach JD, Milby AH, Lonner BS, Balderston RA: Sagittal cervical alignment after cervical disc arthroplasty and anterior cervical discectomy and fusion: results of a prospective, randomized, controlled trial. Spine 34:2001-2007, 2009

4. Baba H, Furusawa N, Imura S, Kawahara N, Tsuchiya H, Tomita K: Late radiographic findings after anterior cervical fusion for spondylotic myeloradiculopathy. Spine 18:2167-2173, 1993

5. Bertagnoli R, Yue JJ, Pfeiffer F, Fenk-Mayer A, Lawrence JP, Kershaw T, et al: Early results after ProDisc-C cervical disc replacement. J Neurosurg Spine 2:403-410, 2005

6. Borden AGB, Rechtman AM, Gershon-Cohen J: The normal cervical lordosis. Radiology 74:806-809, 1960

7. Buckwalter JA: Aging and degeneration of the human intervertebral disc. Spine 20:1307-1314, 1995

8. Cherubino P, Benazzo F, Borromeo U, Perle S: Degenerative arthritis of the adjacent spinal joints following anterior cervical spinal fusion: clinicoradiologic and statistical correlations. Ital J Orthop Traumatol 16:533-543, 1990

9. Davis AG: Injuries of the cervical spine. JAMA 127:149-156, 1945

10. DiAngelo DJ, Foley KT, Morrow BR, Schwab JS, Song J, German JW, et al: In vitro biomechanics of cervical disc arthroplasty with the ProDisc-C total disc implant. Neurosurg Focus 17(3):E7, 2004

11. Döhler JR, Kahn MR, Hughes SP: Instability of the cervical spine after anterior interbody fusion. A study on its incidence and clinical significance in 21 patients. Arch Orthop Trauma Surg 104:247-250, 1985

12. Duggal N, Bertagnoli R, Rabin D, Wharton N, Kowalczyk I: ProDisc-C: an in-vivo kinematic study. J Spinal Disord Tech [in press], 2010

13. Emery SE, Bohlman HH, Bolesta MJ, Jones PK: Anterior cervical decompression and arthrodesis for the treatment of cervical spondylotic myelopathy. Two to seventeen-year followup. J Bone Joint Surg Am 80:941-951, 1998

14. Epstein JA: Common errors in the diagnosis of herniation of the intervertebral disk. IMS Ind Med Surg 39:481-488, 1970

15. Fehlings MJ, Gray R: Editorial. Importance of sagittal balance in determining the outcome of anterior versus posterior surgery for cervical spondylotic myelopathy. J Neurosurg Spine 11:518-520, 2009

16. Ferch RD, Shad A, Cadoux-Hudson TA, Teddy PJ: Anterior correction of cervical kyphotic deformity: effects on myelopathy, neck pain, and sagittal alignment. J Neurosurg Spine 100 (1 Suppl):13-19, 2004

17. Fong SY, DuPlessis SJ, Casha S, Hurlbert RJ: Design limitations of Bryan disc arthroplasty. Spine J 6:233-241, 2006

18. Gore DR, Sepic SB, Gardner GM: Roentgenographic findings of the cervical spine in asymptomatic people. Spine 11:521524,1986 
19. Gwinn DE, Iannotti CA, Benzel EC, Steinmetz MP: Effective lordosis: analysis of sagittal spinal canal alignment in cervical spondylotic myelopathy. Clinical article. J Neurosurg Spine 11:667-672, 2009

20. Harrison DD, Harrison DE, Janik TJ, Cailliet R, Ferrantelli JR, Haas JW, et al: Modeling of the sagittal cervical spine as a method to discriminate hypolordosis: results of elliptical and circular modeling in 72 asymptomatic subjects, 52 acute neck pain subjects, and 70 chronic neck pain subjects. Spine 29:2485-2492, 2004

21. Hilibrand AS, Carlson GD, Palumbo MA, Jones PK, Bohlman $\mathrm{HH}$ : Radiculopathy and myelopathy at segments adjacent to the site of a previous anterior cervical arthrodesis. J Bone Joint Surg Am 81:519-528, 1999

22. Johnson JP, Lauryssen C, Cambron HO, Pashman R, Regan JJ, Anand N, et al: Sagittal alignment and the Bryan cervical artificial disc. Neurosurg Focus 17(6):E14, 2004

23. Katsuura A, Hukuda S, Imanaka T, Miyamoto K, Kanemoto M: Anterior cervical plate used in degenerative disease can maintain cervical lordosis. J Spinal Disord 9:470-476, 1996

24. Katsuura A, Hukuda S, Saruhashi Y, Mori K: Kyphotic malalignment after anterior cervical fusion is one of the factors promoting the degenerative process in adjacent intervertebral levels. Eur Spine J 10:320-324, 2001

25. Kawakami M, Tamaki T, Iwasaki H, Yoshida M, Ando M, Yamada H: A comparative study of surgical approaches for cervical compressive myelopathy. Clin Orthop Relat Res 381:129-136, 2000

26. Kawakami M, Tamaki T, Yoshida M, Hayashi N, Ando M, Yamada H: Axial symptoms and cervical alignments after cervical anterior spinal fusion for patients with cervical myelopathy. J Spinal Disord 12:50-56, 1999

27. Kim SW, Shin JH, Arbatin JJ, Park MS, Chung YK, McAfee PC: Effects of a cervical disc prosthesis on maintaining sagittal alignment of the functional spinal unit and overall sagittal balance of the cervical spine. Eur Spine J 17:20-29, 2008

28. Matsunaga S, Kabayama S, Yamamoto T, Yone K, Sakou T, Nakanishi K: Strain on intervertebral discs after anterior cervical decompression and fusion. Spine 24:670-675, 1999

29. Mummaneni PV, Burkus JK, Haid RW, Traynelis VC, Zdeblick TA: Clinical and radiographic analysis of cervical disc arthroplasty compared with allograft fusion: a randomized controlled clinical trial. J Neurosurg Spine 6:198-209, 2007

30. Pallis C, Jones AM, Spillane JD: Cervical spondylosis; incidence and implications. Brain 77:274-289, 1954

31. Phillips FM, Garfin SR: Cervical disc replacement. Spine 30 (17 Suppl):S27-S33, 2005

32. Pickett GE, Mitsis DK, Sekhon LH, Sears WR, Duggal N: Effects of a cervical disc prosthesis on segmental and cervical spine alignment. Neurosurg Focus 17(3):E5, 2004

33. Pickett GE, Rouleau JP, Duggal N: Kinematic analysis of the cervical spine following implantation of an artificial cervical disc. Spine 30:1949-1954, 2005

34. Pickett GE, Sekhon LH, Sears WR, Duggal N: Complications with cervical arthroplasty. J Neurosurg Spine 4:98-105, 2006

35. Rabin D, Bertagnoli R, Wharton N, Pickett GE, Duggal N: Sagittal balance influences range of motion: an in vivo study with the ProDisc-C. Spine J 9:128-133, 2009

36. Rabin D, Pickett GE, Bisnaire L, Duggal N: The kinematics of anterior cervical discectomy and fusion versus artificial disc: a pilot study. Neurosurgery 61 (3 Suppl):100-104, 2007

37. Rajshekhar V, Arunkumar MJ, Kumar SS: Changes in cervical spine curvature after uninstrumented one- and two-level corpectomy in patients with spondylotic myelopathy. Neurosurgery 52:799-805, 2003

38. Rechtman AM, Borden AGB, Gershon-Cohen J: The lordotic curve of the cervical spine. Clin Orthop 20:208-216, 1961

39. Reitman CA, Hipp JA, Nguyen L, Esses SI: Changes in segmental intervertebral motion adjacent to cervical arthrodesis: a prospective study. Spine 29:E221-E226, 2004

40. Reitman CA, Mauro KM, Nguyen L, Ziegler JM, Hipp JA: Intervertebral motion between flexion and extension in asymptomatic individuals. Spine 29:2832-2843, 2004

41. Sasso RC, Best NM, Metcalf NH, Anderson PA: Motion analysis of Bryan cervical disc arthroplasty versus anterior discectomy and fusion: results from a prospective, randomized, multicenter, clinical trial. J Spinal Disord Tech 21:393-399, 2008

42. Sears WR, Duggal N, Sekhon LH, Williamson OD: Segmental malalignment with the Bryan cervical disc prosthesiscontributing factors. J Spinal Disord Tech 20:111-117, 2007

43. Sears WR, Sekhon LH, Duggal N, Williamson OD: Segmental malalignment with the Bryan Cervical Disc prosthesisdoes it occur? J Spinal Disord Tech 20:1-6, 2007

44. Shim CS, Lee SH, Park HJ, Kang HS, Hwang JH: Early clinical and radiologic outcomes of cervical arthroplasty with Bryan Cervical Disc prosthesis. J Spinal Disord Tech 19:465-470, 2006

45. Takeshima T, Omokawa S, Takaoka T, Araki M, Ueda Y, Takakura Y: Sagittal alignment of cervical flexion and extension: lateral radiographic analysis. Spine 27:E348-E355, 2002

46. Troyanovich SJ, Stroink AR, Kattner KA, Dornan WA, Gubina I: Does anterior plating maintain cervical lordosis versus conventional fusion techniques? A retrospective analysis of patients receiving single-level fusions. J Spinal Disord Tech 15:69-74, 2002

47. Vernon-Roberts B, Pirie CJ: Degenerative changes in the intervertebral discs of the lumbar spine and their sequelae. Rheumatol Rehab 16:13, 1977

48. Wigfield C, Gill S, Nelson R, Langdon I, Metcalf N, Robertson J: Influence of an artificial cervical joint compared with fusion on adjacent-level motion in the treatment of degenerative cervical disc disease. J Neurosurg 96 (1 Suppl):17-21, 2002

49. Yi S, Shin HC, Kim KN, Park HK, Jang IT, Yoon H: Modified techniques to prevent sagittal imbalance after cervical arthroplasty. Spine 32:1986-1991, 2007

50. Yoon DH, Yi S, Shin HC, Kim KN, Kim SH: Clinical and radiological results following cervical arthroplasty. Acta Neurochir (Wien) 148:943-950, 2006

Manuscript submitted February 15, 2010.

Accepted March 29, 2010.

Address correspondence to: Neil Duggal, M.D., Division of Neurosurgery, University Hospital, LHSC, 339 Windermere Road, London, Ontario, Canada, N6A 5A5. email: neil.duggal@lhsc. on.ca. 